\title{
MULTICULTURALISMO E DIREITOS HUMANOS
}

\section{André Viana da Cruz}

Pós-graduando do Curso de Mestrado e Pesquisador do Núcleo de Direito Cooperativo e Cidadania, do Programa de Pós-graduação em Direito da Universidade Federal do Paraná - UFPR.

e-mail: idecos-avc@uol.com.br.

RESUMO: Mediante a compreensão do fenômeno cultural, é possível situar e reconhecer a diversidade existente no mundo, e sob a premissa da pluralidade deve caminhar o entendimento dos direitos humanos. Cultura é o processo acumulativo resultante de toda a experiência histórica das gerações anteriores, e os direitos humanos não podem adotar um critério universalista, consagrando a concepção de um ser abstrato, em um determinado estágio de civilização, conforme concebido e erigido na Declaração Universal dos Direitos Humanos. Nem todos os povos e culturas estavam incluídos no estabelecimento do conteúdo dado aos direitos humanos, que poderiam servir à afirmação da hegemonia ocidental. A concepção universalista defende, em última análise, o projeto da modernidade porque não reconhece o relativismo cultural das coletividades envolvidas na tutela e garantia dos direitos em lume. Para o relativista é ilusória a convicção das teorias-padrão de filosofia moral da era moderna de que poderia fundamentar uma moral universalista. Sob os cânones universalistas, faz-se necessária, portanto, uma linguagem normativa comum, a qual possa servir de base para uma prática de justificação, aceitável para todos, ligando uma cadeia de legitimação igualmente vinculante para todos. A imposição de um padrão moral implica a continuação do colonialismo. Daí porque o universalismo não pode ser adotado em relação aos direitos humanos, pois contempla a necessária proteção da identidade cultural. Reconhecido o multiculturalismo, evita-se a universalização e se garante a alteridade, que é a própria razão de ser dos direitos humanos.

PALAVRAS-CHAVE: Direitos humanos; Multiculturalismo; Relativismo; Universalismo. 


\section{INTRODUÇÃO}

Para Dussel, as culturas "são modos particulares de vida, modos movidos pelo princípio universal da vida humana de cada sujeito em comunidade, a partir de dentro". ${ }^{1}$

A homogeneização da cultura desafia a diversidade de emanações do ser humano e a respectiva identificação.

Segundo Clark, "A aceleração do ritmo de mudança, acompanhada de um aumento perceptível da diversidade cultural, manifestou-se pela primeira vez em conjunção com o homo sapiens, na parte final do Pleitoceno Superior". ${ }^{2}$ O fato de o cérebro do Australopiteco Africano (mais antigo manufaturador) medir $1 / 3$ do nosso leva Geertz $^{3}$, a concluir que a maior parte do crescimento cortical humano foi posterior e não anterior ao início da cultura, o que torna o homem não apenas 0 produtor da cultura, mas, também, produto da cultura. "A cultura desenvolveu-se, pois, simultaneamente com o próprio equipamento biológico e é, por isso mesmo, compreendida como uma das características da espécie, ao lado do bipedismo e de um adequado volume cerebral". ${ }^{4}$

Cultura significa o modo como um grupo de pessoas pensa, crê e vive os instrumentos que fabrica e a forma como faz as coisas ou, ainda, o conjunto de entendimentos, crenças e conhecimentos pertencentes a determinado grupo.

Para Levi-Strauss o que faz a originalidade de cada cultura "está na maneira particular de resolver problemas, de perspectivar valores" e não nas contribuições parcelares de cada civilização.

${ }^{1}$ DUSSEL, Enrique. Ética da Libertação: na idade da globalização e da exclusão. 2.ed. Petrópolis-RJ: Editora Vozes, 2002. p.93.

${ }^{2}$ CLARK, Grahame. A identidade do homem. Tradução: Álvaro Cabral. Rio de Janeiro: Jorge Zahar, 1985.

${ }^{3}$ GEERTZ, Clifford. "A transição para a humanidade”, In: Sol Tax (Org.). Panorama da antropologia. Rio de Janeiro, Fundo de Cultura. Apud Laraia, p.57.

${ }^{4}$ LARAIA, Roque de Barros. Cultura: um conceito antropológico. 14.ed. Rio de Janeiro: Jorge Zahar, 2001. p.58.

5 LÉVI-STRAUSS, Claude. Antropologia Estrutural Dois. Trad. e coordenação de Maria do Carmo Pandolfo. Rio de Janeiro: Tempo Brasileiro, 1976. p.349. 
O termo germânico kultur simbolizava todos os aspectos espirituais de uma comunidade; o termo francês civilization referia-se principalmente às realizações materiais de um povo. "Os dois termos foram sintetizados por Edward Tylor em culture (termo inglês), que em sentido etnográfico é: todo complexo que inclui conhecimentos, crenças, arte, moral, leis, costumes ou qualquer outra capacidade ou hábito adquiridos pelo homem como membro de uma sociedade". ${ }^{6}$

A definição acima se opõe à idéia de aquisição inata (biologismo) e acentua o caráter de aprendizado da cultura, consolidando o pensamento de John Locke, para quem a mente humana é uma caixa vazia quando do nascimento, com capacidade ilimitada para obter conhecimentos.

O homem se diferencia dos demais animais por possuir duas propriedades: comunicação oral e capacidade de fabricação de instrumentos, que tornam mais eficiente seu aparato biológico.

É de se advertir que o aspecto evolucionista unilinear ${ }^{7}$ da teoria de Tylor foi vencido pelo relativismo cultural, ligado à idéia de evolução multilinear. ${ }^{8}$

Franz Boas desenvolveu o particularismo histórico (ou a chamada Escola Cultural Americana), segundo o qual cada cultura segue os seus próprios caminhos em função dos diferentes eventos históricos que enfrentou". 9

Outra contribuição para a compreensão de como a cultura atua sobre o homem é advinda do antropólogo americano Alfred Kroeber, "que demonstrou que graças à cultura a humanidade se distanciou do mundo animal". ${ }^{10} \mathrm{O}$ homem é dotado de um diferencial extraorgânico de adaptação, que o poupou de submeter-se a mutações biológicas, pois, ao contrário das outras espécies, o homem conserva todos

${ }^{6}$ LARAIA. Op. cit., p.25.

7 Tylor acreditava na igualdade da natureza humana, o que possibilitava a comparação de raças do mesmo grau de civilização. Entendia, ainda, que a desigualdade era resultante da desigualdade de estágios no processo de evolução, que estaria disposto numa "escala de civilização". (LARAIA. Op. cit., p.32).

${ }^{8}$ Segundo Laraia, ao tempo do pensamento de Tylor, o que imperava era o evolucionismo unilinear (todas as culturas deveriam passar pelas mesmas etapas de evolução). Ademais, Tylor acreditava na unidade psíquica da humanidade e não reconheceu os múltiplos caminhos da cultura, filiando-se a uma escala evolutiva que consistia em um "processo discriminatório, através do qual diferentes sociedades humanas eram classificadas hierarquicamente, com vantagem aos países europeus". (Idem, p.34).

9 Idem, p.36.

10 Idem, ibidem. 
os órgãos e capacidades de seus antepassados, acrescentando-se a nova faculdade adquirida: a cultura ("que não se torna parte de sua constituição congênita"). ${ }^{11}$

Em última análise, cultura é o processo acumulativo, resultante de toda a experiência histórica das gerações anteriores, e o reconhecimento da diversidade cultural é pressuposto para a aplicação dos direitos humanos.

Nas linhas seguintes, buscar-se-á demonstrar que o multiculturalismo implica o relativismo dos direitos humanos, cuja universalização atende ao projeto da modernidade e resulta no ocultamento do outro.

\section{DIREITOS HUMANOS: EM BUSCA DA UNIVERSALIZAÇÃO}

A Declaração dos Direitos do Homem no fim do século XVIII significava que, desde então, o homem seria a fonte de lei. Destinava-se, também, a ser uma proteção muito necessária numa era em que os indivíduos já não estavam a salvo nos Estados em que haviam nascido. Tais direitos independiam da ordem política e seriam garantidos pelo sistema de valores sociais, espirituais e religiosos. Não se invocava nenhuma autoridade para estabelecê-los; "o próprio homem seria a sua origem e seu objetivo último". ${ }^{12}$

A declaração dos direitos humanos referia-se a um ser humano abstrato (universalizado), dentro de determinada civilização. "Como a humanidade, desde a Revolução Francesa, era concebida à margem de uma família de nações, tornou-se gradualmente evidente que o povo, e não o indivíduo, representava a imagem do homem". ${ }^{13}$ Supunha-se que os direitos humanos independiam dos direitos nacionais.

Os Direitos do Homem foram conceituados como "inalienáveis", pois se pensava que eram independentes dos governos. Contudo, no momento em que os seres humanos deixavam de ter um governo próprio, nenhuma instituição ou autoridade Ihes protegia.

O conceito de direitos humanos foi tratado de modo marginal pelo pensamento político do século XIX, e nenhum partido liberal do século XX houve por

11 LARAIA, Op. cit., p.39.

12 ARENDT, Hannah. Origens do Totalitarismo. Tradução de Roberto Raposo. São Paulo: Companhia das Letras, 1989, p.324.

13 Idem, p.325. 
bem incluí-los em seu programa, eis que os direitos civis supostamente personificavam e enunciavam sob forma de leis os eternos Direitos do Homem. "Todos os seres humanos eram cidadãos de algum tipo de comunidade política: se as leis do seu país não ao atendiam às exigências dos Direitos do Homem, esperava-se que nos países democráticos eles as mudassem através da legislação, e nos despóticos, por meio de ação revolucionária". ${ }^{14}$

Os Direitos do Homem mostraram-se inexeqüíveis sempre que surgiam pessoas que não eram cidadãos de algum Estado soberano. Perda dos lares e perda da proteção do governo foram as duas grandes supressões verificadas contra as pessoas privadas de direitos. Sem um lugar peculiar no mundo e sem poderem ser assimilados em nenhum território. Os países civilizados ofereciam asilo sem que isso fosse positivado; ademais, as novas categorias de refugiados eram demasiado numerosas para serem atendidas e os novos refugiados não se enquadravam nos critérios de perseguição política (dificultando sobremaneira a concessão de asilo).

"A calamidade dos que não têm direitos não decorre do fato de terem sido privados da vida, da liberdade ou da procura da felicidade (...) mas do fato de não pertencerem a qualquer comunidade". ${ }^{15}$ Verificou-se completa privação de direitos antes que o direito à vida fosse ameaçado. Nem a segurança física, nem a liberdade de opinião alteram sua situação de privação de direitos, pois o prolongamento de suas vidas é devido à caridade e nada do que pensam tem qualquer importância.

Os direitos humanos deveriam permanecer válidos mesmo que um ser humano seja expulso da comunidade humana. Sob tal apreensão, foi concebida e erigida a Declaração Universal dos Direitos Humanos, em 10 de dezembro de 1948, buscando-se um alcance universal e universalista.

Ocorre que nem todos os povos e culturas estavam incluídos no estabelecimento do conteúdo dado aos direitos humanos, que poderiam servir à afirmação da hegemonia ocidental. A maioria que países africanos e asiáticos não participaram na formulação da Declaração Universal de Direitos Humanos porque, como vítimas de colonização, ${ }^{16}$ eles não eram os sócios das Nações

\footnotetext{
14 Idem, p.326-327.

15 Idem, p.329.

${ }^{16}$ Notadamente a América Latina.
} 
Unidas. Garantiu-se, por exemplo, um território aos judeus; mas em detrimento aos palestinos, se lhes negando a alteridade.

Defender os direitos humanos é, em última análise, defender o projeto da modernidade. ${ }^{17}$ Isto porque não se reconhece o relativismo cultural das coletividades envolvidas na tutela e garantia de mencionados direitos.

\section{MULTICULTURALISMO, RELATIVISMO E DIREITOS HUMANOS}

A racionalidade que preside a ciência moderna admite a variedade interna, mas refuta o senso comum e os estudos humanísticos. ${ }^{18}$ Trata-se de um modelo totalitário que nega o caráter racional a todas as formas de conhecimento que não se pautarem epistemológica e metodologicamente nas bases da modernidade. "O Estado moderno e seu direito foram criados para um determinado sistema econômico ou modo de produção, a liberdade, segurança e igualdade propugnadas pela Constituição francesa tinha paradigmas claros que garantiam, em última instância, os direitos individuais e, ainda mais precisamente, o direito individual de propriedade". ${ }^{19}$

"O relativismo defende a tese de que os sistemas morais só possuem validade relativa, não podendo, por conseguinte, reivindicar uma validade universal, uma validade supratemporal e invariável de cultura para cultura". ${ }^{20}$ Para o relativista, é ilusória a convicção das teorias-padrão de filosofia moral da era moderna de que poderia fundamentar uma moral universalista.

Existe um contexto cultural que não é rompido por uma moral transcendental.

"A moral sempre só existe numa forma particular; as pessoas que são membros de uma comunidade moral, que formam sua identidade individual e cultural no horizonte de convicções partilhadas acerca de valores, obviamente consideram a moral vigente como um sistema de valores que é objetivamente vinculante e sobrepuja interesses conflitantes. Mas

17 SOUZA FILHO, Carlos Frederico Marés de. Aula ministrada em 18/11/2004, parte do programa da disciplina Direitos Humanos e Cooperativismo.

18 SANTOS, Boaventura de Sousa. Para um Novo Senso Comum: a ciência, o direito e a política na transição paradigmática. Vol. I: A Crítica da Razão Indolente: contra o desperdício da experiência. 4.ed. São Paulo: Cortez Editora, 2002. p.60-61

19 Idem, p.313-314. 
os limites de validade dessa moral terminam nas fronteiras da área de influência cultural que expressa sua peculiaridade nesse sistema moral."21

Todos os conceitos-chave estão semanticamente impregnados pela singularidade do respectivo contexto cultural. "Até mesmo os princípios mais genéricos têm uma coloração cultural e são, por isso, inadequados para um conjunto de regras cuja pretensão de validade não varie de acordo com a respectiva cultura". ${ }^{22}$

Não existe uma argumentação fundamentadora capaz de transcender os distintos sistemas de moral e, por sua vez, relativizar esses sistemas em sua validade.

Para Kersting, o relativismo ético é uma tese filosófica sobre o alcance da validade de juízos morais, não se confundindo com 0 relativismo cultural (multiculturalismo). Este pode ensejar aquele. ${ }^{23}$

"Se não há princípios morais de validade universal, que comprometem de igual maneira cada pessoa, independentemente de sua situação de vida, (...) também não se podem encontrar regras normativas para organizar a interação dessas diferentes esferas culturais". ${ }^{24}$

"No embate entre universalismo e relativismo está em jogo a autocompreensão da modernidade cultural, o igualitarismo em relação aos direitos humanos nela desenvolvido e o caráter modelar das formas liberais de organização do mercado, do Estado de direito, do Estado social e da democracia"25. Sob os cânones universalistas, "faz-se necessária, portanto, uma linguagem normativa comum, a qual possa servir de base para uma prática de justificação, aceitável para todos, que consiga ligar uma cadeia de legitimação igualmente vinculante para todos". ${ }^{26}$

A imposição de um padrão moral implica continuação do colonialismo. Daí porque o universalismo não pode ser adotado de forma irrestrita, nem sequer em relação aos direitos humanos. Estes, no pensamento de Kersting, devem ser

\footnotetext{
${ }^{20}$ KERSTING, Wolfgang. Universalismo e Direitos Humanos. Porto Alegre: EDIPUCRS, 2003, p.82.

${ }^{21}$ Idem, p.83.

22 Idem, ibidem.

${ }^{23}$ Idem, p.84.

${ }^{24}$ Idem, ibidem.

${ }^{25}$ Idem, p.85.
} 
submetidos a um tratamento semântico. ${ }^{27}$ Mas de onde se extraem os significados senão dos contextos culturais?

Prosseguindo com sua crítica ao relativismo, Kersting afirma que um conceito de direitos humanos válido, em termos de fundamentação teórica, é resistente ao relativismo. Isto ocorre quando, numa situação multiculturalista, pode ser reconhecido além-fronteiras, numa "argumentação que atribua ao conceito de direitos humanos um significado independente de toda coloração cultural e nãocarente de hermenêutica cultural". ${ }^{28}$

Mas a hermenêutica cultural propugnada nos parece uma concessão ao relativismo. Pois estaríamos negando uma moral transcendental kantiana e adentrando na pós-metafísica. Isto se faz possível por uma genealogia dos valores morais, uma crítica da origem como Herkunft (movimento descontínuo de forças) e não mais como Ursprung (essência exata da coisa). ${ }^{29}$ Uma crítica do valor dos valores que se propõe à superação da metafísica na medida em que não parte da afirmação de valores eternos, mas se justifica na história, na "fisiologia", na "psicologia", na vontade de verdade que em Nietzsche significa vontade de poder. A história tradicional supõe uma essência na origem. A origem genealógica supõe o acaso, o conflito. Não há uma evolução linear dos valores desde seu fundamento distante, mas há um jogo de forças infindável construído peça por peça a partir de figuras estranhas entre si.

O relativismo ético se constrói a partir da diversidade de meios culturais. Mas existem estruturas recorrentes em determinados conteúdos que podem nortear a fundamentação dos direitos humanos.

Embora seja o homem um animal político, e, portanto, um ser cultural, podemos reduzi-lo à condição de ser desprovido de atribuições para localizar o cerne do conceito de direitos humanos. Estamos tratando de um sujeito nãotranscendental, mas finito, mortal, vulnerável (neste ponto concordamos com Kersting), mas não podemos esquecer que tais características variam culturalmente

\footnotetext{
${ }^{26}$ Idem, p.86.

27 Idem, p.89.

28 Idem, p.91.

${ }^{29}$ FOUCAULT, Michel. Nietzsche, a genealogia e a história. In: Microfísica do Poder. 16.ed. Rio de
} Janeiro: Edições Graal, 2001. passim. 
(v.g., a vulnerabilidade para um tuaregue seguramente tem sentido diverso daquilo que considera um habitante de um grande centro urbano).

Considerados em seu interior, os direitos humanos podem ser divididos em condicionais (necessários para que os seres humanos tenham a oportunidade de levar uma vida pacífica e livre de violência - necessidade antropológica e existencial) e programáticos (nos quais se delineiam as condições que precisam estar adicionalmente cumpridas para as pessoas levarem uma vida boa - marco institucional do cumprimento em termos de ética cidadã). No primeiro caso, encontra-se o direito à vida, à incolumidade física e à segurança básica; no segundo, o direito à liberdade e à igualdade políticas, à democracia e autodeterminação política, ao Estado de direito e constitucionalismo, a um abastecimento básico suficiente, do ponto de vista da ética cidadã, e a uma condição assegurada de membro numa república mundial. ${ }^{30}$

Segundo Kersting, a epistemologia e a prática dos direitos humanos programáticos são bem mais complicadas do que as dos direitos relativos à existência, nos quais está em pauta a área biológica central da antropologia (antropologia física?), não suas áreas culturalistas periféricas, mas o conceito de natureza humana.

"Qualquer que seja o contexto cultural específico que determine a ética de condução de vida dos seres humanos e a produção coletiva de sentido vinculante para eles, independentemente disso deve-se afirmar que pressupostos fundamentais precisam se cumpridos para que as pessoas possam levar, dentro de tais contextos, uma vida suportável, que lhes proporcione sentido."31

Vê-se uma projeção no paradigma da vida concreta, mas, ainda assim é de se fazer ressalva da necessidade de um relativismo, pois, por exemplo, não podemos exigir que para aplacar a fome tenha um hindu que romper com seus valores culturais e se alimente de carne bovina. Mas "o universal e o transcendental são, como tais, inóspitos e necessitam de múltipla contextualização e particularização para mostrar eficácia". ${ }^{32}$

\footnotetext{
${ }^{30}$ KERSTING. Op. cit., p.95-96.

31 Idem, p.99.

32 Idem, p.102.
} 
Mas como conciliar a necessidade de um conteúdo mínimo aos direitos humanos, conferido igualmente a todos os povos e respeitadas as diferenças culturais? A resposta não é tão simples, mas nos parece oportuno o posicionamento de Sousa Santos:

"O multiculturalismo progressista pressupõe que o princípio da igualdade seja utilizado de par com o princípio do reconhecimento da diferença. A hermenêutica diatópica pressupõe a aceitação do seguinte imperativo transcultural: temos o direito de ser iguais quando a diferença nos inferioriza; temos o direito a ser diferentes quando a igualdade nos descaracteriza." 33

Para o sociólogo lusitano, que aponta o imperialismo cultural e o epistemicídio como parte da trajetória histórica da modernidade ocidental, compete à hermenêutica diatópica por ele proposta transformar os direitos humanos numa política cosmopolita que ligue em rede línguas diferentes de emancipação social e as torne mutuamente inteligíveis e traduzíveis, sendo este o projeto de uma concepção multicultural. ${ }^{34}$

Segundo Abdullahi Ahmed An-Na'im ${ }^{35}$, as violações de direitos humanos refletem a falta ou fraqueza de legitimidade cultural de padrões internacionais em uma sociedade. A legitimidade cultural pode não ser a base ou até mesmo o primário determinante de complacência com padrões de direitos humanos, mas é extremamente significante. $O$ autor adota uma aproximação construtiva ao problema da legitimidade cultural de normas de direitos humanos. A interpretação terá que ser empreendida de uma maneira sensível, legítima, sendo necessário tempo para sua aceitação e implementação pela população.

\section{CONCLUSÕES}

A metafísica nos levou a tratar tudo como objeto, mas o ser humano é mais do que aquilo que podemos apreender transcendentalmente. A cultura é integrante

33 SANTOS, Boaventura de Sousa. Reconhecer para libertar: os caminhos do cosmopolismo multicultural. V. III: Reinventar a Emancipação Social: para novos manifestos. Rio de Janeiro: Civilização Brasileira, 2003, p.458.

\footnotetext{
${ }^{34}$ Idem, p.458.
} 
do ser humano e não pode ser meramente objetificada. Parafraseando Heidegger, é necessário buscar os caminhos que foram deixados quando tudo foi polarizado pela técnica.

É inegável "a coexistência de formas culturais ou de grupos caracterizadores por culturas diferentes no seio das sociedades modernas", ${ }^{36}$ e, por conseguinte, não se pode adotar um critério reducionista para circunscrever as emanações que representam as diversas culturas.

"Muitas vezes o indivíduo de uma coletividade não consegue se aperceber do valor de sua própria cultura, imbuído que está no seu próprio individualismo". ${ }^{37}$ Este é o projeto da modernidade, que busca reduzir tudo a uma única racionalidade universalista.

O fenômeno cultural é maior e integrante do próprio ser coletivo. Portanto, o relativismo dos direitos humanos é necessário para a proteção da identidade cultural.

É necessário reconhecer o multiculturalismo, pois a universalização nivela os valores a uma racionalidade dos colonizadores, negando a alteridade, que é a própria razão de ser dos direitos humanos.

\section{BIBLIOGRAFIA}

ARENDT, Hannah. Origens do Totalitarismo. Tradução de Roberto Raposo. São Paulo: Companhia das Letras, 1989.

CLARK, Grahame. A identidade do homem. Tradução: Álvaro Cabral. Rio de Janeiro: Jorge Zahar, 1985.

DUSSEL, Enrique. Ética da Libertação: na idade da globalização e da exclusão. 2. ed. PetrópolisRJ: Editora Vozes, 2002.

FOUCAULT, Michel. Microfísica do Poder. 16. ed. Rio de Janeiro: Edições Graal, 2001.

HAYDEN, Patrick. The Philosophy of Human Rights. St. Paul: Paragon House, 2001.

KERSTING, Wolfgang. Universalismo e Direitos Humanos. Porto Alegre: EDIPUCRS, 2003.

35 AN-NA'IM, Abdullahi Ahmed. Direitos Humanos no Mundo Muçulmano: condições sociopolíticas e imperativos bíblicos. In: The Philosophy of Human Rights. HAYDEN, Patrick (Coord.). St. Paul: Paragon House, 2001.

${ }^{36}$ Idem, p.26. 
LARAIA, Roque de Barros. Cultura: um conceito antropológico. 14. ed. Rio de Janeiro: Jorge Zahar, 2001.

LÉVI-STRAUSS, Claude. Antropologia Estrutural Dois. Trad. e coordenação de Maria do Carmo Pandolfo. Rio de Janeiro: Tempo Brasileiro, 1976.

SANTOS, Boaventura de Sousa. Para um novo senso comum: a ciência, o direito e a política na transição paradigmática. Vol. I: A Crítica da Razão Indolente: contra o desperdício da experiência. 4. ed. São Paulo: Cortez Editora, 2002.

SANTOS, Boaventura de Sousa. Reconhecer para libertar: os caminhos do cosmopolismo multicultural. Vol. III: Reinventar a Emancipação Social: para novos manifestos. Rio de Janeiro: Civilização Brasileira, 2003.

SOUZA FILHO, Carlos Frederico Marés de. Bens Culturais e Proteção Jurídica. Porto Alegre: UE/Porto Alegre, 1997.

SOUZA FILHO, Carlos Frederico Marés de. "Os direitos invisíveis" In: OLIVEIRA, Francisco de; PAULI, Maria Célia (Orgs.). Os sentidos da Democracia: políticas do dissenso e hegemonia global. Rio de Janeiro: Vozes Editora, 1999.

${ }^{37}$ SOUZA FILHO, Carlos Frederico Marés de. Bens Culturais e Proteção Jurídica. p.37. 